\title{
Spectroscopic characterization of manganese-doped alkaline earth lead zinc phosphate glasses
}

\author{
S SREEHARI SASTRY ${ }^{1, *}$ and B RUPA VENKATESWARA RAO ${ }^{1,2}$ \\ ${ }^{1}$ Department of Physics, Acharya Nagarjuna University, Nagarjunanagar 522 510, India \\ ${ }^{2}$ Department of Physics, V.R. Siddhartha Engineering College, Vijayawada 520 007, India
}

MS received 3 March 2014; revised 22 July 2014

\begin{abstract}
Alkaline earth lead zinc phosphate glasses doped with Mn(II) are characterized by spectroscopic techniques like X-ray diffraction (XRD), UV-visible, differential scanning calorimetry (DSC), electron paramagnetic resonance (EPR), Fourier transform infrared (FTIR) and Raman. Optical absorption spectrum exhibits four bands which are characteristic of $\mathrm{Mn}$ (II) in distorted octahedral site symmetry. The crystal field parameter Dq and Racah interelectronic-repulsion parameters $B$ and $C$ have been evaluated. All investigated samples exhibit EPR signals which are characteristic to the $\mathrm{Mn}^{2+}$ ions. The shapes of spectra are also changed with varying alkaline earth ions content. FTIR spectra show specific vibrations of phosphate units. The characteristic Raman bands of these glasses due to stretching and bending vibrations were identified and analysed by varying alkaline earth content. The intensity and frequency variations for the characteristic phosphate group vibrations have been correlated with the changes of the structural units present in these glasses. Depolymerization of the phosphate chains in all the glasses is observed with replacement of alkaline earth content by spectroscopic studies. This leads to a strong decrease of the average chain length and a small decrease of the average $\mathrm{P}-\mathrm{O}-\mathrm{P}$ bridging angle with replacement of alkaline earth content.
\end{abstract}

Keywords. Glasses; UV-vis; DSC; EPR; FTIR; Raman spectral studies; Racah parameters.

\section{Introduction}

Recent technological applications have generated more importance in the studies of different types of glasses owing to their structural properties. ${ }^{1,2}$ One of them is phosphate glass, which owing to their hygroscopic nature and volatility was not considered to have industrial and technological applications. But in the recent developments of novel compositions of superior physical and chemical properties such as high thermal expansion coefficients, ${ }^{3}$ high ultra-violet and far infrared transmission, ${ }^{4}$ low melting and softening temperatures, make these glasses potential candidates for many technological applications, such as medical use and sealing materials. ${ }^{5}$

The interest in glasses containing transition metal ions has grown ${ }^{6}$ because these glasses have properties of technological importance. Among all the transition metal ions, manganese $\left({ }^{55} \mathrm{Mn}\right)$ have been recurrently used as paramagnetic probes to investigate the structure and properties of vitreous systems, as manganese ions have a strong demeanor on the magnetic and optical properties of the glass. In glass matrices manganese ions exist in different valence states occupying tetrahedral or octahedral sites in glass network. The content of manganese in various environments and valence states in the glasses depends on the quantitative properties

\footnotetext{
*Author for correspondence (sreeharisastry@yahoo.com)
}

of modifiers and glass formers, size of the ions in the glass structure, their field strength, mobility of the modifier cation, etc. ${ }^{7}$ Hence, connection between state and position of manganese ion and electrical properties of glass containing mobile ions like $\mathrm{Mg}^{2+} / \mathrm{Ca}^{2+} / \mathrm{Sr}^{2+} / \mathrm{Ba}^{2+}$ is expected to be interesting. Spectroscopic techniques made to obtain information on some of structural and dynamic phenomenon of a material; and to identify the site symmetry around the transition metal ions in glasses. ${ }^{8}$ The aim of present investigation is to study the nature of site symmetry of $\mathrm{Mn}^{2+}$ in alkaline earth lead zinc phosphate glasses along with compositional variation of alkaline earth content.

\section{Experimental}

The glasses under study were prepared from chemically pure AnalaR grade reagents such as $\mathrm{P}_{2} \mathrm{O}_{5}, \mathrm{~Pb}_{3} \mathrm{O}_{4}, \mathrm{ZnO}, 0.1 \mathrm{~mol} \%$ of $\mathrm{MnO}$ and $\mathrm{MgO}, \mathrm{CaO}, \mathrm{SrO}, \mathrm{BaO}$ were added as an intermediate compound to each glass composition. The weighed batches were melted in porcelain crucibles at $1100^{\circ} \mathrm{C}$ for $1 \mathrm{~h}$. The melts were rotated several times and the homogenized melts were poured in slightly warmed brass molds of the required dimensions. The prepared samples were immediately transferred to an annealing furnace regulated at $300^{\circ} \mathrm{C}$ for about $5 \mathrm{~h}$ to relieve mechanical strains and cracking of the glass samples. The compositions of the glass samples employed in the study are given in table 1. 
Table 1. Glass compositions ( $\mathrm{mol} \%)$.

\begin{tabular}{lc}
\hline Samples & Composition (mol\%) \\
\hline TG4A & $59.9 \mathrm{P}_{2} \mathrm{O}_{5}-10 \mathrm{~Pb}_{3} \mathrm{O}_{4}-10 \mathrm{ZnO}-20 \mathrm{MgO}-0.1 \mathrm{MnO}$ \\
TG4B & $59.9 \mathrm{P}_{2} \mathrm{O}_{5}-10 \mathrm{~Pb}_{3} \mathrm{O}_{4}-10 \mathrm{ZnO}-20 \mathrm{CaO}-0.1 \mathrm{MnO}$ \\
TG4C & $5939 \mathrm{P}_{2} \mathrm{O}_{5}-10 \mathrm{~Pb}_{3} \mathrm{O}_{4}-10 \mathrm{ZnO}-20 \mathrm{Sro}-0.1 \mathrm{MnO}$ \\
TG4D & $59.9 \mathrm{P}_{2} \mathrm{O}_{5}-10 \mathrm{~Pb}_{3} \mathrm{O}_{4}-10 \mathrm{ZnO}-20 \mathrm{BaO}-0.1 \mathrm{MnO}$ \\
\hline
\end{tabular}

The amorphous nature of the glass is investigated through the X-ray diffraction (XRD) patterns recorded on powder samples at room temperature using Philips X-ray generator (Model PW1170) with $\mathrm{CuK}_{\alpha}$ radiation $(\lambda=1.5418 \AA$ ) in the $2 \theta$ ranges from $10^{\circ}$ to $70^{\circ}$, with a step size of $2^{\circ}$ per minute. The differential scanning calorimetry (DSC) measurements were performed using Netzsch DSC 204 instrument. A small amount of material about 5-10 mg was taken in the aluminium pan of the DSC set-up and scanned at a heating rate of $10^{\circ} \mathrm{C} \mathrm{min}^{-1}$. The optical absorption spectra of these glasses were recorded to a resolution of $0.1 \mathrm{~nm}$ at room temperature in the spectral wavelength range covering from 200 to $900 \mathrm{~nm}$ using JASCO model V-670 UV-vis-NIR spectrophotometer. Electron paramagnetic resonance (EPR) spectra were made at room temperature through BRUKERER073 series of EPR spectrometer which operates in the $\mathrm{X}$-band frequency $(9.4 \mathrm{GHz})$ at $100 \mathrm{kHz}$ field modulation. The magnetic field was scanned from 0 to $800 \mathrm{mT}$ and the microwave power used was $1 \mathrm{~mW}$. The infrared spectra of alkali earth lead zinc phosphate glasses were recorded on SHIMADZU 8201 PC FTIR spectrophotometer in the range $4000-400 \mathrm{~cm}^{-1}$ using $\mathrm{KBr}$ pellets. With Raman spectrometer (Lab RAM HR-800-HORIBAJOBINYVON) equipped with argon ion laser $514.25 \mathrm{~nm}$, which eliminates the problem of sample fluorescence and photo-decomposition. The glass samples were subjected for the Raman spectra in the range $200-3500 \mathrm{~cm}^{-1}$ with $1.0 \mathrm{~mW}$ laser power. The formulae and process applied here to resolve the physical properties in the study were put to test in earlier works of authors. ${ }^{9,10}$

\section{Results and discussion}

The chemical composition of glass samples which are shown in table 1 are prepared for the present study. The change in atomic geometrical configuration, co-ordination number, cross-link density and the dimensions of the interstitial space in the glass network decides the density. Hence, the density is a tool in revealing the degree of change in the structure with any glass composition. ${ }^{11}$ The increase in density for the glass system reveals the change in the structure of the glass with replacement of alkaline earth content. The density of a glass is found to be very sensitive to the ionic size and atomic weight. ${ }^{12}$ The data in table 2 indicate that average molecular weight increases from TG4A to TG4D glass which influences density, refractive index and other physical properties. The density and refractive index of TG4D glass is more, this can be due to the addition of $\mathrm{Ba}^{2+}$ provides ionic
Table 2. Physical properties of $\mathrm{Mn}^{2+}$-doped alkaline earth lead zinc phosphate glasses.

\begin{tabular}{lcccc}
\hline Physical property & TG4A & TG4B & TG4C & TG4D \\
\hline $\begin{array}{l}\text { Refractive index (nd) at } \\
589.3 \mathrm{~nm}\end{array}$ & 1.6405 & 1.6450 & 1.6550 & 1.6605 \\
$\begin{array}{l}\text { Density, } d\left(\mathrm{~g} \mathrm{~cm}^{-3}\right) \\
\text { Average molecular weight, }\end{array}$ & 3.6275 & 3.6309 & 3.8710 & 3.9324 \\
$\quad 1$ (g) & 169.852 & 173.007 & 182.515 & 192.457 \\
Mean atomic volume & & & & \\
$\quad\left(\mathrm{g} \mathrm{cm}^{-3}\right.$ per atom $)$ & 8.5210 & 8.5804 & 8.6712 & 8.9065 \\
Molar volume, $V_{\mathrm{m}}\left(\mathrm{cm}^{3}\right)$ & 46.8234 & 47.6485 & 47.1493 & 48.9431 \\
Optical basicity $\Lambda_{\mathrm{th}}$ & 0.4132 & 0.4441 & 0.4451 & 0.4525 \\
\hline
\end{tabular}

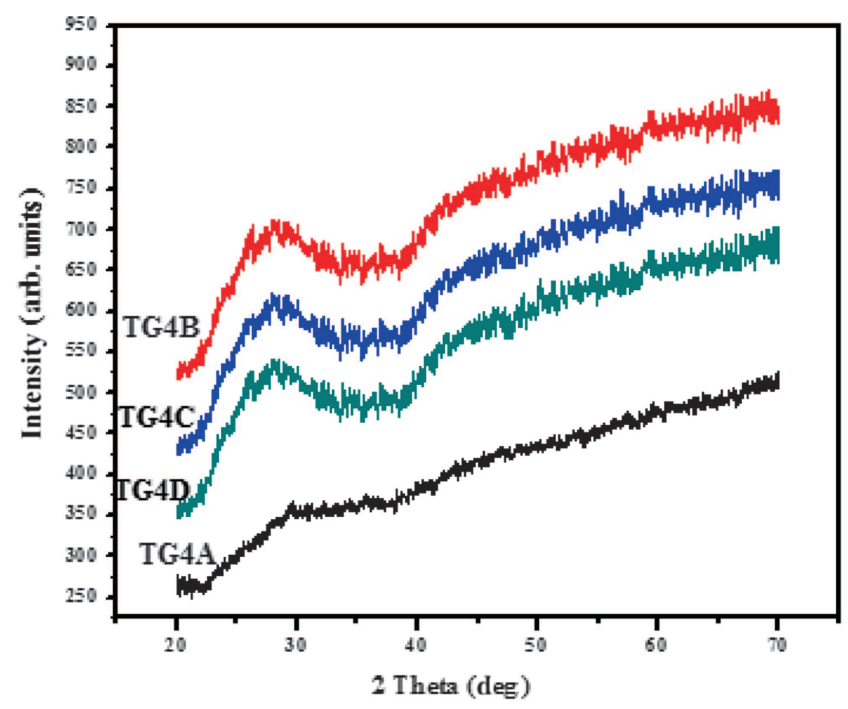

Figure 1. XRD spectra of $\mathrm{Mn}^{2+}$-doped alkaline earth lead zinc phosphate glasses.

cross-linking between non-bridging oxygen's and increases the bond strengthof this cross-link is expected to improve chemical durability. The increase in refractive index is attributed to the generation of non-bridging oxygen (NBO). Molar volume is gradually increased with successive substitution of $\mathrm{MgO} / \mathrm{CaO} / \mathrm{SrO} / \mathrm{BaO}$, suggests increased free space within glass structure and changes in the structure. ${ }^{13,14}$ Basicity parameter slightly increases from glass TG4A to TG4D. High optical basicity means high electron donor ability o oxide ions to the cations. The optical basicity can be used to classify the covalent/ionic character of the glasses since an increasing $\Lambda_{\text {th }}$ indicates decreasing covalence. ${ }^{15}$ Deviation in properties also infers that environment around manganese ions is different in different glasses which are due to replacement of alkali earth oxide effects.

Figure 1 shows the XRD patterns of $\mathrm{Mn}^{2+}$-doped alkaline earth lead zinc phosphate glass systems. No significant crystalline peaks recorded in the patterns, it is confirmed here the amorphous nature of glass samples.

DSC monitors heat effects allied with the phase transitions and chemical reactions as a role of temperature. DSC 
thermograms of present glass system are shown in figure 2. All the glasses exhibited an endothermic change due to the glass transition temperature $T_{\mathrm{g}}$ occurred between 360 and $380^{\circ} \mathrm{C}$. For higher temperatures all the sampled glasses exhibited an exothermic change due to crystallization temperature $T_{\mathrm{c}}$ reported between 400 and $425^{\circ} \mathrm{C}$. The values of $T_{\mathrm{g}}, T_{\mathrm{c}}$ and $T_{\mathrm{c}}-T_{\mathrm{g}}$ are presented in table 3 . The $T_{\mathrm{c}}-T_{\mathrm{g}}$ values present the information on the stability of the glass against devitrification. ${ }^{16}$

The network modifiers directly influence the $T_{\mathrm{g}}$ because glass transition involves modification of chemical bonds between the glass former and glass modifiers. Generally, the $T_{\mathrm{g}}$ of oxide glasses increase with the bond strength, cross-link density and closeness of packing. ${ }^{17}$ The introduction of a glass modifier such as RO into the oxide glass modifies the oxide network. ${ }^{18-20}$

On the basis of the above literature reports, the results obtained in the present study can be interpreted as follows. The increase in glass transition temperature values reflects an increase of cross-link strength of glass network as $\mathrm{Mg}^{2+}$ or $\mathrm{Ca}^{2+}$ or $\mathrm{Sr}^{2+}$ or $\mathrm{Ba}^{2+}$ ions are introduced in the phosphate glass. The increased cross-linking appears to be responsible for better chemical durability of the doped glasses. Thus glass with maximum $T_{\mathrm{g}}$ value is the most durable one out of all other glasses studied.

The absorption spectrum shows $\mathrm{Mn}^{2+}\left(d^{5}\right)$ can occur in glasses both in tetrahedral and octahedral environments. The UV-visible absorption spectra of $\mathrm{Mn}^{2+}$-doped alkaline earth lead zinc phosphate glass samples is shown in figure 3 . It is observed that, four bands nearly at around 370, 406, 450 and 530 are assigned to the transitions ${ }^{6} A_{1 \mathrm{~g}}(S) \rightarrow{ }^{4} T_{1 \mathrm{~g}}(G)$, ${ }^{6} A_{1 \mathrm{~g}}(S) \rightarrow{ }^{4} T_{2 \mathrm{~g}}(G),{ }^{6} A_{1 \mathrm{~g}}(S) \rightarrow{ }^{4} A_{1 \mathrm{~g}}(G)+{ }^{4} E_{\mathrm{g}}(G)$ and ${ }^{6} A_{1 \mathrm{~g}}(S) \rightarrow{ }^{4} T_{2 \mathrm{~g}}(D)$, characteristic of $\mathrm{Mn}^{2+}$ ions in octahedral symmetry ${ }^{21-23}$ and the band positions are presented in table 4 . The analysis shows that manganese ions exist mainly in $\mathrm{Mn}^{2+}$ state, occupy tetrahedral positions. Optical spectra have been analysed in the framework of crystal field theory. ${ }^{24}$ The excited quartet states ${ }^{4} G,{ }^{4} P,{ }^{4} D$ and ${ }^{4} F$ of $\mathrm{Mn}^{2+}$ ions in octahedral crystal field are located above the ground ${ }^{6} S$ state

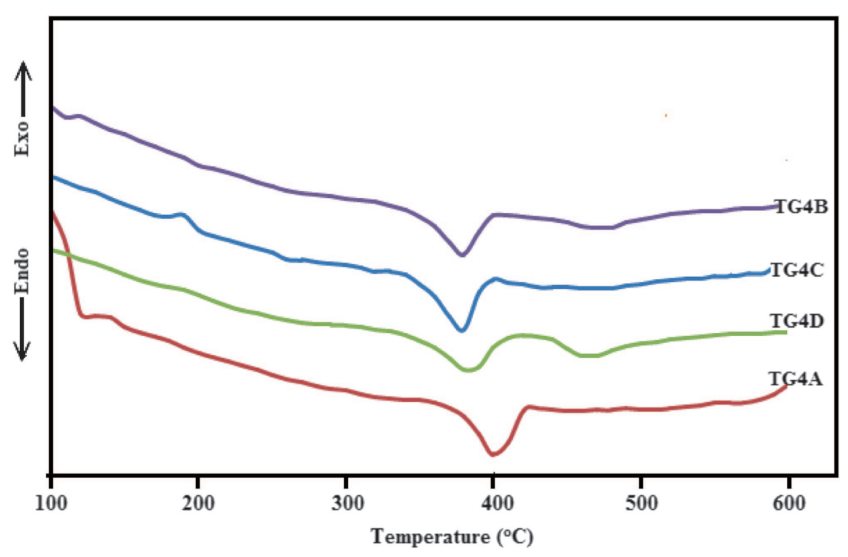

Figure 2. DSC pattern of $\mathrm{Mn}^{2+}$-doped alkaline earth lead zinc phosphate glasses. and trigonal crystal field splits four levels into ten sublevels. Therefore, all the transitions from the ground sextet ${ }^{6} S$ to the excited levels are spin-forbidden, intensity of optical absorption lines of $\mathrm{Mn}^{2+}$ are weak and in addition, $\mathrm{Mn}^{2+}$ ion had a $3 d^{5}$ configuration. The absorption band at around $450 \mathrm{~nm}$ was asymmetric, indicating that the octahedral ligand field had suffered a tetrahedral deformation by the Jahn-Teller effect. The ligand field bands are sharp, when the energy expressions for the transition are independent of Dq whereas the bands are broad when they depend on Dq. The crystalfield parameter Dq and the inter-electronic repulsion parameters $B$ and $C$ have been evaluated by energy matrices ${ }^{25}$ for the $d^{5}$ configuration. In the analysis of the optical spectrum, Trees' correction parameter ${ }^{26}$ ' $\alpha$ ' $=76 \mathrm{~cm}^{-1}$ has also been incorporated to obtain a good fit between the observed and calculated values. The crystal fields and inter-electronic repulsion parameters are given in table 5 . The values of $\mathrm{Dq} / B$ and $C / B$ represent structural distortion and which is observed to be high in BaO-based glass. The obtained $B$ values decreases gradually from TG4A glass to TG4D glass, such decrease indicates an increase in average distance of $\mathrm{Mn}-\mathrm{O}$ in the glass matrix. ${ }^{27}$

The absorption edge study in the UV region is a useful method to understand the optical transition and electronic band structure in glasses. The principle of this technique is that a photon with energy greater than the band gap energy will be absorbed. The photoconductivity spectral response of such materials rises sharply at about the same frequency as the optical absorption edge. ${ }^{28}$ The absorption edge, at low energy, normally follows the Urbach rule. ${ }^{29}$ Such an edge can occur in glassy materials from inter-band transitions relating the tails of localized states, the density of which falls off exponentially with energy in the band gap. ${ }^{30}$ The absorption coefficient $\alpha(v)$ for direct and indirect optical transitions is given by following equation: ${ }^{31}$

$$
\alpha(v)=\frac{a_{0}\left[h v-E_{\mathrm{opt}}\right]^{n}}{h v},
$$

where exponent $n=1 / 2$ for an allowed direct transition, while $n=2$ for an allowed indirect transition, $\alpha_{0}$ is a constant related to the extent of the band tailing and $E_{\text {opt }}$ the optical band gap energy. The absorption coefficient, $\alpha(v)$, can be determined near the absorption edge of different photon energies for all glass samples. The values of optical band ga energy $\left(E_{\text {opt }}\right)$ can be determined from the plot of $(\alpha h v)^{1 / 2}$

Table 3. Data on DSC traces of of $\mathrm{Mn}^{2+}$-doped alkaline earth lead zinc phosphate glasses.

\begin{tabular}{lccc}
\hline Sample & $T_{\mathrm{g}}\left({ }^{\circ} \mathrm{C}\right)$ & $T_{\mathrm{c}}\left({ }^{\circ} \mathrm{C}\right)$ & $T_{\mathrm{c}}-T_{\mathrm{g}}\left({ }^{\circ} \mathrm{C}\right)$ \\
\hline TG4A & 379 & 422 & 43 \\
TG4B & 365 & 406 & 41 \\
TG4C & 362 & 401 & 39 \\
TG4D & 359 & 423 & 64 \\
\hline
\end{tabular}



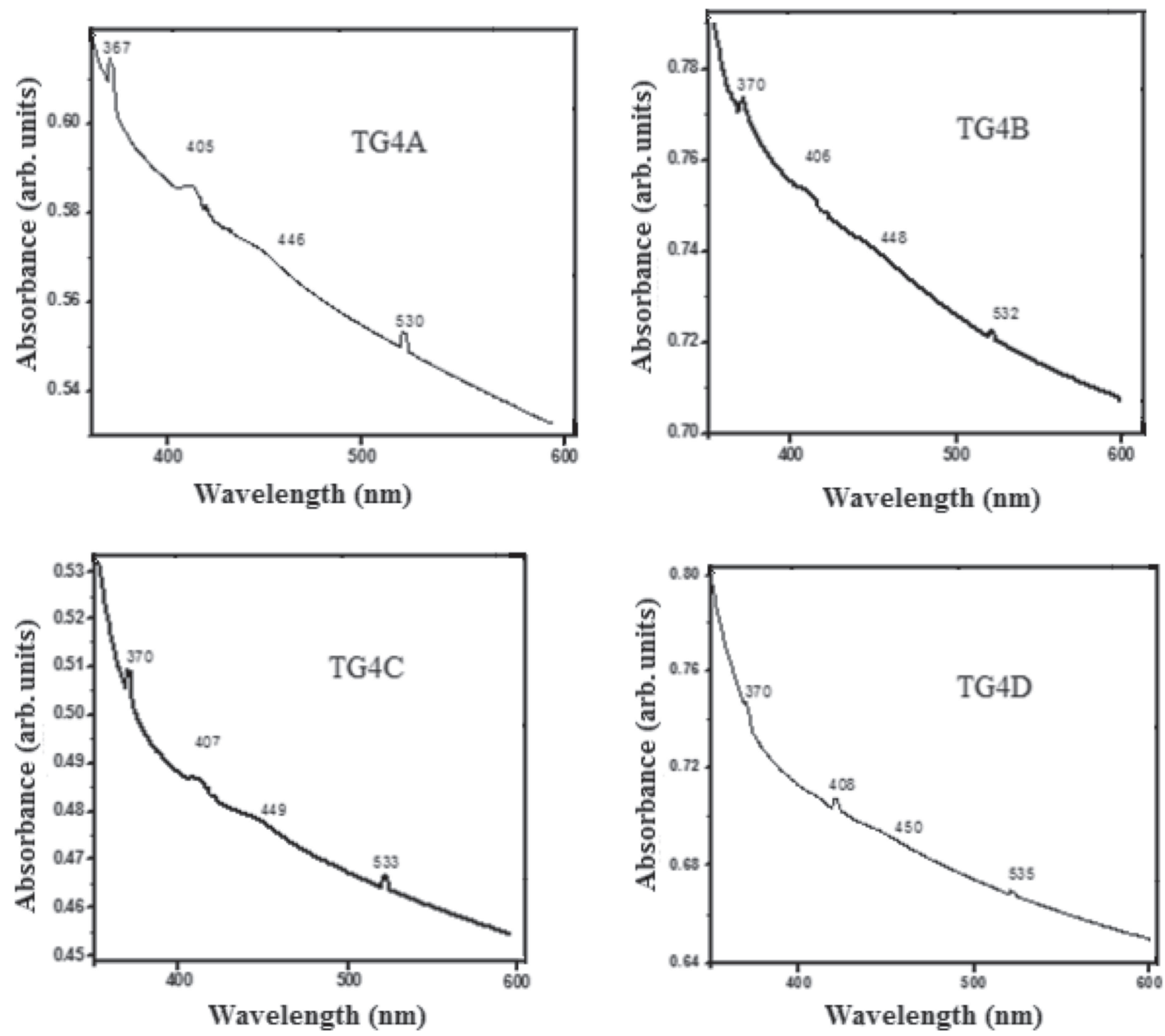

Figure 3. Optical absorption spectra of $\mathrm{Mn}^{2+}$-doped alkaline earth lead zinc phosphate glasses.

$v s$. photon energy $(h v)$ (Tauc's plot), for allowed indirect transitions.

Figure 4 shows Tauc's plots of $\mathrm{Mn}^{2+}$-doped alkaline earth lead zinc phosphate glasses. Optical band gap $\left(E_{\mathrm{opt}}\right)$ and Urbach energy $(\Delta E)$ values are presented in table 6. Urbach energy decreases with replacement of alkaline earth, shows the structural disorder of the system. Smaller is the value of Urbach energy, greater is the structural stability of the glass system. It is observed that $\mathrm{BaO}$-based glass (TG4D) have low value of structural disorder, which indicates the strong structural stability. The band gap energy calculations indicate that the glass systems are direct semiconductors.

The EPR spectra of $\mathrm{Mn}^{2+}$ are analysed using the spinHamiltonian of the form

$$
H=g \beta B S+S A I+S D S,
$$

where $g$ is the isotropic factor, $\beta$ the Bohr magneton, $B$ the external magnetic field, $S$ the vector operator of the electron spin momentum and $A$ the hyperfine interaction parameter,
$I$ the vector operator of nuclear spin momentum and $D$ the zero field splitting parameter.

EPR spectra of $\mathrm{Mn}^{2+}$ in a series of glasses have shown that the spectra have been characterized by an intense resonance signal at around $g=2.0$ with six line hyperfine pattern, an absorption around $g=4.3$ which is a characteristic of $\mathrm{Mn}^{2+}$ ions with a nuclear spin $I=5 / 2 .{ }^{32}$ The ${ }^{55} \mathrm{Mn}$ hyperfine structure has two substantial benefits. (a) It commonly allows explicit assignments of positions of complex resonance lines to manganese and (b) the magnitude of hyperfine splitting constant provides a measure of bonding between $\mathrm{Mn}^{2+}$ ions and its neighbouring ligands. ${ }^{33}$ In $d^{5}$ transition metal ions, it is well-known that axial distortion of octahedral symmetry gives rise to three Kramer's doublets $| \pm 5 / 2\rangle$, $| \pm 3 / 2\rangle$ and $| \pm 1 / 2\rangle .{ }^{34}$ As the crystal field splitting is normally greater than the Zeeman field, the resonances observed are due to transitions in the Zeeman field split Kramer's doublets.

Recorded EPR spectra show resonance line due to $\mathrm{Mn}^{2+}$ $\left(3 d^{5},{ }^{6} S_{5 / 2}\right)$ paramagnetic ions for all glasses. The structure of 
Table 4. Optical absorption band positions of $\mathrm{Mn}^{2+}$-doped alkaline earth lead zinc phosphate glasses.

\begin{tabular}{llccc}
\hline & & & \multicolumn{2}{c}{ Wavenumber $\left(\mathrm{cm}^{-1}\right)$} \\
\cline { 4 - 5 } Sample & Transitions & Wavelength $(\mathrm{nm})$ & Observed & Calculated \\
\hline \multirow{4}{*}{ TG4A } & ${ }^{6} A_{1 \mathrm{~g}}(S) \rightarrow{ }^{4} T_{1 \mathrm{~g}}(G)$ & 530 & 18,867 & 18,715 \\
& ${ }^{6} A_{1 \mathrm{~g}}(S) \rightarrow{ }^{4} T_{2 \mathrm{~g}}(G)$ & 446 & 22,421 & 22,462 \\
& ${ }^{6} A_{1 \mathrm{~g}}(S) \rightarrow{ }^{4} A_{1 \mathrm{~g}}(G)+{ }^{4} E_{\mathrm{g}}(G)$ & 405 & 24,691 & 24,742 \\
& ${ }^{6} A_{1 \mathrm{~g}}(S) \rightarrow{ }^{4} T_{2 \mathrm{~g}}(D)$ & 368 & 27,173 & 27,240 \\
& ${ }^{6} A_{1 \mathrm{~g}}(S) \rightarrow{ }^{4} T_{1 \mathrm{~g}}(G)$ & 532 & 18,796 & 18,634 \\
TG4B & ${ }^{6} A_{1 \mathrm{~g}}(S) \rightarrow{ }^{4} T_{2 \mathrm{~g}}(G)$ & 448 & 22,321 & 22,347 \\
& ${ }^{6} A_{1 \mathrm{~g}}(S) \rightarrow{ }^{4} A_{1 \mathrm{~g}}(G)+{ }^{4} E_{\mathrm{g}}(G)$ & 406 & 24,630 & 24,652 \\
& ${ }^{6} A_{1 \mathrm{~g}}(S) \rightarrow{ }^{4} T_{2 \mathrm{~g}}(D)$ & 370 & 27,027 & 27,099 \\
& ${ }^{6} A_{1 \mathrm{~g}}(S) \rightarrow{ }^{4} T_{1 \mathrm{~g}}(G)$ & 533 & 18,761 & 18,624 \\
TG4C & ${ }^{6} A_{1 \mathrm{~g}}(S) \rightarrow{ }^{4} T_{2 \mathrm{~g}}(G)$ & 449 & 22,271 & 22,335 \\
& ${ }^{6} A_{1 \mathrm{~g}}(S) \rightarrow{ }^{4} A_{1 \mathrm{~g}}(G)+{ }^{4} E_{\mathrm{g}}(G)$ & 407 & 24,570 & 24,642 \\
& ${ }^{6} A_{1 \mathrm{~g}}(S) \rightarrow{ }^{4} T_{2 \mathrm{~g}}(D)$ & 370 & 27,027 & 27,083 \\
& ${ }^{6} A_{1 \mathrm{~g}}(S) \rightarrow{ }^{4} T_{1 \mathrm{~g}}(G)$ & 535 & 18,691 & 18,597 \\
TG4D & ${ }^{6} A_{1 \mathrm{~g}}(S) \rightarrow{ }^{4} T_{2 \mathrm{~g}}(G)$ & 450 & 22,222 & 22,296 \\
& ${ }^{6} A_{1 \mathrm{~g}}(S) \rightarrow{ }^{4} A_{1 \mathrm{~g}}(G)+{ }^{4} E_{\mathrm{g}}(G)$ & 408 & 24,509 & 24,612 \\
& ${ }^{6} A_{1 \mathrm{~g}}(S) \rightarrow{ }^{4} T_{2 \mathrm{~g}}(D)$ & 370 & 27,027 & 27,036 \\
\hline
\end{tabular}

Table 5. Crystal fields and inter-electronic repulsion parameters of $\mathrm{Mn}^{2+}$-doped alkaline earth lead zinc phosphate glasses.

\begin{tabular}{lcccc}
\hline Sample & Dq $\left(\mathrm{cm}^{-1}\right)$ & $B\left(\mathrm{~cm}^{-1}\right)$ & $C\left(\mathrm{~cm}^{-1}\right)$ & $\alpha\left(\mathrm{cm}^{-1}\right)$ \\
\hline TG4A & 780 & 725 & 3200 & 76 \\
TG4B & 780 & 716 & 3200 & 76 \\
TG4C & 780 & 715 & 3200 & 76 \\
TG4D & 780 & 712 & 3200 & 76 \\
\hline
\end{tabular}

the spectra strongly depends on manganese content of samples. The EPR spectra are presented in figure 5. EPR spectra observed in alkaline earth lead zinc phosphate glass matrix consist of a well-resolved sextet centred at $g=2.0$ with a broad background signal underneath the sextet and very well absorption centred at $g=4.3$, which is characteristic for isolated $\mathrm{Mn}^{2+}$ ions in rhombic distorted octahedral environment, as shown in figure 5 .

The $g=2.0$ resonance line is known to arise from central $M_{\mathrm{S}}=|-1 / 2\rangle \rightarrow|+1 / 2\rangle$ transition where $M_{\mathrm{S}}$ is the effective spin component. The six-line multiplet results from hyperfine interaction of electron spin with ${ }^{55} \mathrm{Mn}$ nucleus $(I=$ $5 / 2$ ). This isotropic signal at $g=2.0$ is due to $\mathrm{Mn}^{2+}$ ions in an environment close to octahedral symmetry. With successive replacement of alkaline earth content into glass matrix there is a small variation in $g$-values and it is shown in table 7, which indicates that ions that might be responsible for EPR lines broadening and participated in dipolar interaction. The hyperfine structure (hfs) is suitable to isolated $\mathrm{Mn}^{2+}$ ions in octahedral sites that are alienated well enough from each other to avoid strong dipolar interactions. $g$ factor value and well-resolved hfs support this statement and also give evidence for the predominantly ionic character

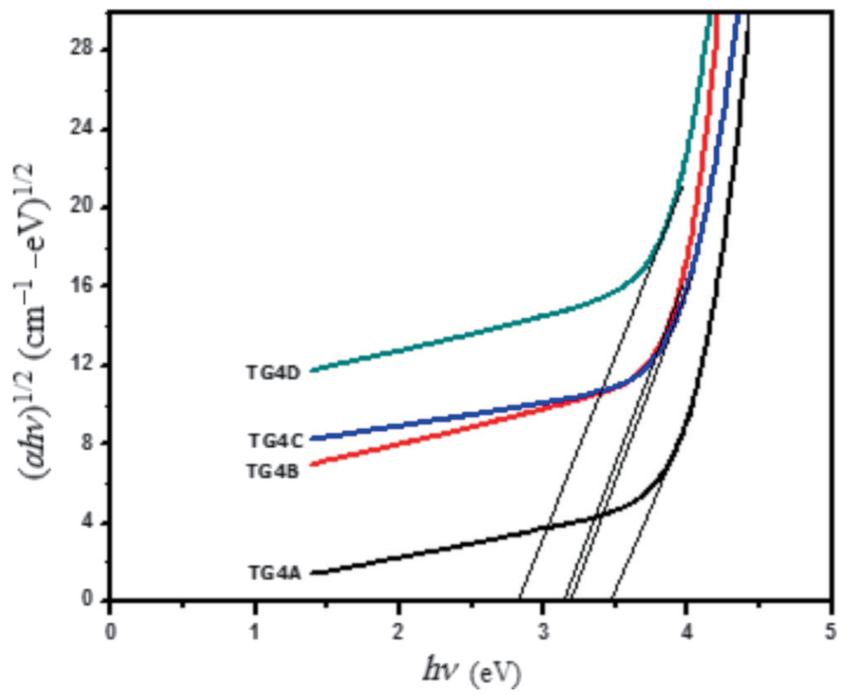

Figure 4. Tauc's plots of $\mathrm{Mn}^{2+}$-doped alkaline earth lead zinc phosphate glasses.

of the bonding between $\mathrm{Mn}^{2+}$ and the $\mathrm{O}^{2-}$ ions generating the octahedral symmetric ligand field. From figure 5 it was concluded that resonance signal at $g \approx 2.0$ which is due to $\mathrm{Mn}^{2+}$ ion in an environment close to the octahedral symmetry. ${ }^{35}$ EPR spectral studies reveal the nature of the bonding is dominantly ionic and its site symmetry is octahedral.

FTIR absorption spectra gives information about molecular vibrations as well as rotation associated with a covalent bond. Transmission spectra of all the phosphate glasses accumulated in the range $1400-400 \mathrm{~cm}^{-1}$. The FTIR spectra are interpreted on the basis of the vibration of the phosphate glass structural units close to the subsequent crystalline 
analogues. ${ }^{36,37}$ FTIR spectra for present glass systems are shown in figure 6 . Bands at 1280 and $1320 \mathrm{~cm}^{-1}$ is especially meaningful, as it is due to the anti-symmetrical vibrations of $\mathrm{PO}_{2}^{-}$groups $/ \mathrm{P}=\mathrm{O}$ stretching. ${ }^{38}$ The band $\sim 1200$ $\mathrm{cm}^{-1}$ is consign to the symmetrical stretching vibrations $\left(v_{\mathrm{s}}(\mathrm{O}-\mathrm{P}-\mathrm{O})\right)$ group of non-bridging oxygen in phosphate chain. ${ }^{39}$ The band at $1180 \mathrm{~cm}^{-1}$ is due to the vibrations of $\mathrm{PO}_{3}^{2-}$ groups at the end of chains. ${ }^{40}$ The observed band at $\sim 1080 \mathrm{~cm}^{-1}$ is assigned to a normal vibrational mode of $\mathrm{PO}_{4}^{3-}$ group arising out of $\nu_{3}$-symmetric stretching. The bands around $950-980 \mathrm{~cm}^{-1}$ are due to P-O-P asymmetric bending vibrations/this region may also consist of bands due to pyrophosphate groups $\mathrm{P}_{2} \mathrm{O}_{7}^{4-}$. An asymmetric stretching vibration $v_{\text {as }}(\mathrm{P}-\mathrm{O}-\mathrm{P})$ is observed at $910 \mathrm{~cm}^{-1}$ in the spectra is the characteristic of $\mathrm{Q}^{1}$ group. ${ }^{37}$ The bands at about $900-1100 \mathrm{~cm}^{-1}$ can be assigned to phosphate units with progressive replacement of alkali earth oxides from $\mathrm{MgO}$ to $\mathrm{BaO} .{ }^{41}$ Another band in the region of $760-780 \mathrm{~cm}^{-1}$ is due to $\mathrm{P}-\mathrm{O}-\mathrm{P}$ symmetric stretching vibrations. The band at $660 \mathrm{~cm}^{-1}$ is attributed to P-O-P. The band at about $700 \mathrm{~cm}^{-1}$ is ascribed to $\mathrm{P}-\mathrm{O}-\mathrm{P}$ symmetrical stretching vibration mode. ${ }^{42}$ The vibrational modes observed at 530,540 and $580 \mathrm{~cm}^{-1}$ for all the glasses are due to the bending mode of the phosphate polyhedra and/or $\mathrm{Pb}-\mathrm{O}$ and $\mathrm{Zn}-\mathrm{O}$ vibrations. The formation of these bonds replaces easily hydrolysable $\mathrm{P}-\mathrm{O}-\mathrm{P}$ bonds. ${ }^{43}$ Some bands are shifted toward higher wavenumber, i.e., those corresponding to the $\mathrm{P}=\mathrm{O}$ double bond, both

Table 6. Optical band gap $\left(E_{\text {opt }}\right)$ and Urbach $(\Delta E)$ energies of $\mathrm{Mn}^{2+}$-doped alkaline earth lead zinc phosphate glasses.

\begin{tabular}{lcc}
\hline Samples & $\begin{array}{c}\text { Optical band gap energy } \\
E_{\text {opt }}(\mathrm{eV})\end{array}$ & $\begin{array}{c}\text { Urbach energy } \\
\Delta E(\mathrm{eV})\end{array}$ \\
\hline TG4A & 3.458 & 0.256 \\
TG4B & 3.130 & 0.284 \\
TG4C & 3.174 & 0.232 \\
TG4D & 2.815 & 0.198 \\
\hline
\end{tabular}

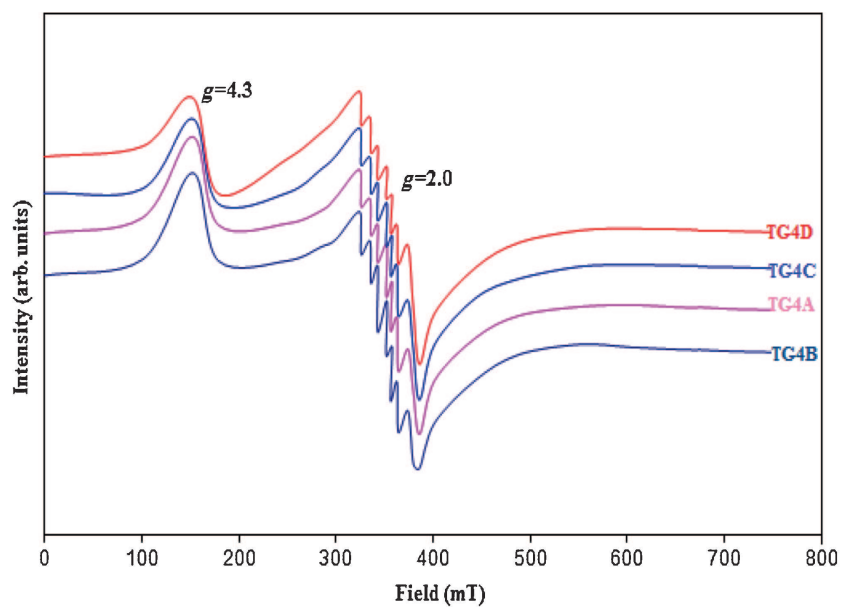

Figure 5. EPR spectra of $\mathrm{Mn}^{2+}$-doped alkaline earth lead zinc phosphate glasses. of symmetric and antisymmetric stretching $\mathrm{P}-\mathrm{O}-\mathrm{P}$ modes and harmonic bending mode of $\mathrm{P}-\mathrm{O}-\mathrm{P}$ bond. The effect of successive addition of alkaline earth is observed in the increase of the peak at $1080 \mathrm{~cm}^{-1}$ and the decrease of the peaks at $730 \mathrm{~cm}^{-1}$ which clearly indicate the increase of the pyrophosphate units on the expense of the decrease of the metaphosphate units. These activities can be due to the depolymerization process inside the glass network. ${ }^{44}$ With successive substitution of $\mathrm{MgO} / \mathrm{CaO} / \mathrm{SrO} / \mathrm{BaO}$ content, glass matrix leads to more $\mathrm{P}=\mathrm{O}$ bonds breakage and to form $\mathrm{P}-\mathrm{O}-\mathrm{Mg} / \mathrm{P}-\mathrm{O}-\mathrm{Ca} / \mathrm{P}-\mathrm{O}-\mathrm{Sr} / \mathrm{P}-\mathrm{O}-\mathrm{Ba}$ bonds. ${ }^{45-48}$ Alkaline earth oxides enter the glass network interstitially, as a network modifier; and we know that when modifier cations are added to phosphate glasses depolymerization takes and formation of ionic cross bonding between phosphate chains.

The prevalence of any particular $Q$ species is dependent on the metal oxide content of the glass composition. The addition of metal ions will make $Q^{n}$ species present in the phosphate glass network. ${ }^{49}$ In phosphate glasses with $\left[\mathrm{P}_{2} \mathrm{O}_{5}\right]$ $>50 \mathrm{~mol} \%$, the structural types of units are $Q^{3}$ and $Q^{2}$ tetrahedra. ${ }^{50}$

The changes of the Raman spectra with composition are used to deduce the structural evolution of the samples. The basic structural element of phosphate glass is the $\left[\mathrm{PO}_{4}\right]$ tetrahedron. The addition of modifying oxides leads to the scission of $\mathrm{P}-\mathrm{O}-\mathrm{P}$ bonds and to the network depolymerization. ${ }^{51}$ The Raman spectra of the studied glasses are shown in

Table 7. Summary of the data on EPR of $\mathrm{Mn}^{2+}$-doped alkaline earth lead zinc phosphate glasses.

\begin{tabular}{lccc}
\hline Sample & $g($ signal 1$)$ & $g($ signal 2$)$ & $A\left(10^{-4} \mathrm{~cm}^{-1}\right)$ \\
\hline TG4A & 2.0285 & 4.2988 & 89.75 \\
TG4B & 2.0256 & 4.2988 & 89.62 \\
TG4C & 2.0244 & 4.2988 & 90.97 \\
TG4D & 2.0273 & 4.2988 & 89.99 \\
\hline
\end{tabular}

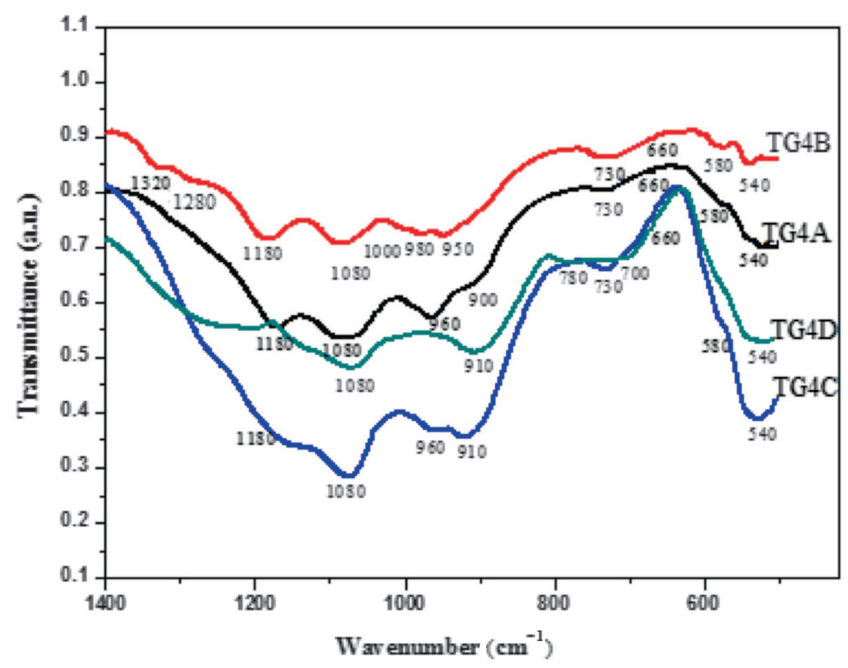

Figure 6. FTIR spectra of $\mathrm{Mn}^{2+}$-doped alkaline earth lead zinc phosphate glasses. 


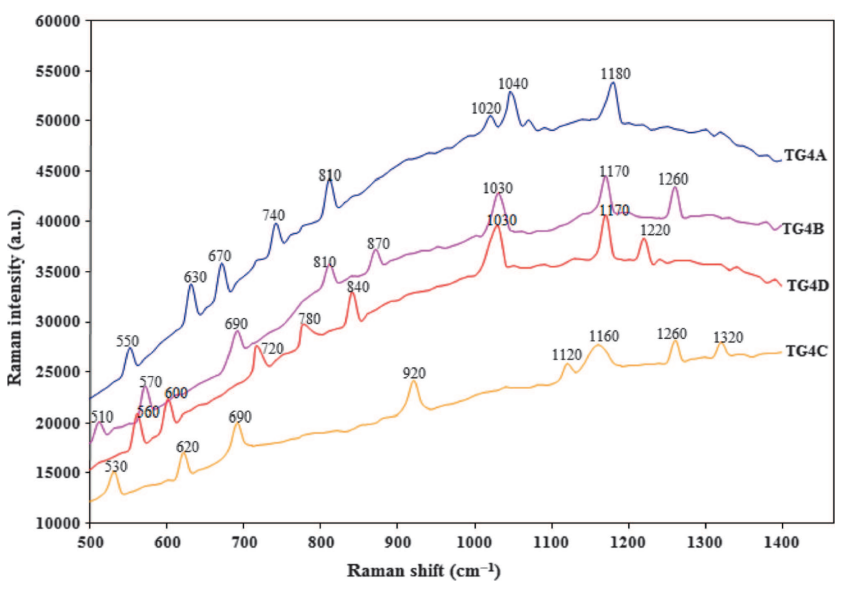

Figure 7. Raman spectra of $\mathrm{Mn}^{2+}$-doped alkaline earth lead zinc phosphate glasses.

figure 7. The change in peak position of bands could be help to get more insight into the effect of alkaline earth on the phosphate network. On the basis of the assignments of Raman spectra for the present glasses, the bands at 1120$1170 \mathrm{~cm}^{-1}$ attributed to vibrations of $\mathrm{PO}_{2}^{-}$in $Q^{2}$ units, band $1320 \mathrm{~cm}^{-1}$ due to the $\mathrm{P}=\mathrm{O}$ symmetric stretching vibrations. ${ }^{52,53}$ The peaks between 1120 and $1140 \mathrm{~cm}^{-1}$ is elucidated by $Q^{2}$ groups interacting with different cations such as $\mathrm{Mg}^{2+} / \mathrm{Ca}^{2+} / \mathrm{Sr}^{2+} / \mathrm{Ba}^{2+} .54$ Band at $1250 \mathrm{~cm}^{-1}$ is attributed to $\left(\mathrm{PO}_{2}\right)_{\text {as }}$ stretch, $Q^{2}$ units. ${ }^{55}$ The depolarized Raman band at about $1260 \mathrm{~cm}^{-1}$ is assigned to asymmetric stretching vibrations of the non-bridging oxygen's against $\mathrm{P}$ atoms. Band at around 800 and $1020-1040 \mathrm{~cm}^{-1}$ are related to the symmetric stretching mode of bridging ( $\mathrm{P}-\mathrm{O}-\mathrm{P})$ sym and non-bridging $\left(\mathrm{PO}_{2}\right)$ sym oxygen atoms in $Q^{1}$ phosphate terahedra, ${ }^{56}$ band at $920 \mathrm{~cm}^{-1}$ assigned to vibration in $\mathrm{PO}_{2}^{-}$ and $\mathrm{PO}_{3}^{-}$groups. ${ }^{57}$ The band at $780 \mathrm{~cm}^{-1}$ is due to $(\mathrm{P}-\mathrm{O}-\mathrm{P})_{\mathrm{s}}$ stretch in very short phosphate chains or in ring structure. ${ }^{58}$ Band at $\sim 650 \mathrm{~cm}^{-1}$ due to the vibration of $\mathrm{P}-\mathrm{O}-\mathrm{P}$ in-chain, bands at about $670-690 \mathrm{~cm}^{-1}$ are assigned to the symmetric in-plane bending vibration, $v_{\mathrm{s}}(\mathrm{P}-\mathrm{O}-\mathrm{P})$, of bridging oxygens connecting two $\mathrm{PO}_{4}$ tetrahedra. ${ }^{59}$ The bands at $550-580 \mathrm{~cm}^{-1}$ are a sign of the (O-P-O) bending in the $Q^{1}$ structure and/or $\mathrm{Zn}-\mathrm{O}$ tetrahedral bonds indication. ${ }^{60}$

FTIR and Raman spectra of the studied glasses are influenced by the network modifiers as well as transition metal oxide. Depolymerization of phosphate chains in all the glasses is observed with replacement of alkaline earth content by spectroscopic studies. This leads to a strong decrease of the average chain length and a small decreasing of the average $\mathrm{P}-\mathrm{O}-\mathrm{P}$ bridging angle with replacement of alkaline earth content.

\section{Conclusions}

XRD diffractograms reveal the amorphous nature of manganese-doped alkaline earth lead zinc phosphate glasses. From optical absorption spectra of $\mathrm{Mn}^{2+}$ ions in glasses, it is concluded that the site symmetry of the $\mathrm{Mn}^{2+}$ ion is tetragonally distorted octahedral. Optical band gap energy and Urbach energy are found to be dependent upon variation of alkaline earth content. DSC results indicate that barium ions increase cross-link density and enhance mean bond strength in TG4D glass. EPR investigations indicated the presence of two signals: an isotropic one at $g=2.0$ which is due to $\mathrm{Mn}^{2+}$ in an environment close to the octahedral symmetry and a very well absorption centred at $g=4.3$ which is characteristic for isolated $\mathrm{Mn}^{2+}$ ions in cubic symmetric sites slightly tetragonally or rhombically distorted. From EPR and optical spectral studies reveals the nature of the bonding is dominantly ionic and its site symmetry is octahedral. The predominant phosphate units occurring in doped sampled glasses are noticed by Raman spectra and it is supported by FTIR spectra also. Vibrational spectral features indicate a depolymerization process of the phosphate network with successive substitution of alkaline earth content. This process implies an increase of the number of non-bridging oxygen.

\section{Acknowledgements}

We gratefully acknowledge UGC DRS LEVEL III program No. F.530/1/DRS/2009 (SAP-1), dated 09-02-2009 and DST FIST program no. DST/FIST/PSI-002/2011 dated 20-122011, New Delhi, to the Department of Physics, ANU, for providing financial assistance.

\section{References}

1. Gautam C R, Kumar D, Parkash O and Singh P 2013 Bull. Mater. Sci. 36461

2. Motke S G, Yawale S P and Yawale S S 2002 Bull. Mater. Sci. 2575

3. Loong C K, Suzuya K, Price D L, Sales B C and Boatner L A 1997 Physica B 241-243 890

4. Liu H S and Chin T S 1997 Phys. Chem. Glasses 38123

5. Keun Lee Y and Choi S H 2008 J. Korean Acad. Periodontol. 38273

6. Kreidl N J 1990 J. Non-Cryst. Solids 123337

7. Ravikumar R V S S N, Ikeda K, Chandrasekhar A V, Reddy Y P, Rao P S and Jun Y 2003 J. Phys. Chem. Solids 642433

8. Osipov A A, Osipova L M and Eremyashev V E 2013 Glass Phys. Chem. 39105

9. Srinivasa Rao A, Rupa Venkateswara Rao B, Prasad M V V K S, Shanmukha Kumar J V, Jayasimhadri M, Rao J L and Chakradhar R P S 2009 Physica B 4043717

10. Weber M J, Saroyan R A and Ropp R C 1981 J. Non-Cryst. Solids $\mathbf{4 4} 137$

11. Gaafar M S, Marzouk S Y and Mady H 2009 Philos. Mag. 89 2213

12. Shelby J E 2005 Introduction to glass science and technology (Cambridge: Royal Society of Chemistry) 2nd ed

13. Sanjay S, Kishore N S and Agarwal A 2009 J. Alloys Compd. 48752

14. Saddeek Y B 2009 J. Alloys Compd. 46714 
15. Duffy J A and Ingram M D 1975 J. Inorg. Nucl. Chem. 371203

16. Hurby A 1972 Czech. J. Phys. B 221187

17. Ray N H 1974 J. Non-Cryst. Solids 15423

18. Shelby J E 1983 J. Am. Ceram. Soc. 66225

19. Button D P, Tondon R, King C, Velez M H, Tuller H L and Uhlmann U R 1982 J. Non-Cryst. Solids 49129

20. Martin S W and Angell C A 1984 J. Non-Cryst. Solids 66429

21. Dummy R 1980 J. Non-Cryst. Solids 41273

22. Srinivasa Rao A, Sreedher B and Rao J L 1992 J. Non-Cryst. Solids 144169

23. Machado I E C, Prado L, Gomes L, Prison J M and Martinelli J R 2004 J. Non-Cryst. Solids 348113

24. Henderson B 2000 Crystal-field engineering of solid-state 424 laser materials (Cambridge: Cambridge Press)

25. Tanabe Y and Sugano S 1954 J. Chem. Soc. Jpn. 9753

26. Trees R E 1951 Phys. Rev. 83756

27. Burns R G 1993 Mineralogical applications of crystal field theory (Cambridge: Cambridge University Press)

28. Mort N F and Davis E A 1971 Electronic processes in noncrystalline materials (Oxford: Clarendon)

29. Urbach F 1953 Phys. Rev. 921324

30. Tauc J and Abeles F 1970 Optical properties of solids (Berlin: Springer)

31. Abdel-Baki M, El-Diasty F and Wahab F A A 2006 Opt. Commun. 26165

32. Viviani D, Faivre F, Levelut C and Smaihi M 2006 J. Phys. Chem. B 1107281

33. Van Wieringen J S 1955 Discuss. Faraday Soc. 19118

34. Abragam A and Bleaney B 1970 Electron paramagnetic resonance of transition ions (Oxford: Clarendon)

35. Giridhar G, Rangacharyulu M, Ravikumar R V S S N and Sambasiva Rao P 2009 IOP Conf. Ser.: Mater. Sci. Eng. 2 012058

36. Efimov A M 1996 J. Non-Cryst. Solids 2031

37. Montagne L, Palavit G and Mairesse G 1996 Phys. Chem. Glasses 37206

38. Elisa M et al 2010 J. Optoelectron. Adv. Mater. 41301

39. Rohaizada A, Hussina R, Syaqilah Aziza N A, Uninga R and Boharia N Z I 2013 Jurnal Teknologi 62119
40. Le Saout G, Simon P, Fayon F, Blin A and Villas Y $2002 J$. Raman Spectrosc. 33740

41. Yiannopoulos Y D, Chryssikos G D and Kamitsos E I 2001 Phys. Chem. Glasses 42164

42. El-Ahdal M A, Antar E M, Mahmoud H H and Ezz-Eldin F M 2011 J. Appl. Sci. Res. 71434

43. Abid M, Elmoudane M and Et-tabirou M 2002 Phys. Chem. Glasses $\mathbf{4 3} 267$

44. Metwalli E, Karabulut M, Sidebottom D L, Morsi M M and Brow R K 2004 J. Non-Cryst. Solids 344128

45. Peng Y B and Day D E 1984 Glass Technol. 5166

46. Hudgens J J and Martin S W 1994 J. Am Ceram. Soc. 76 1691

47. Bunker B C, Arnold G W and Wilder J A 1984 J. Non-Cryst. Solids 64291

48. Ardelean I, Andronache C, Câmpean C and Pascuta P 2004 Mod. Phys. Lett. B 1845

49. Van Wazer J R 1958 Phosphorous and its compounds (New York: Inter-Science) vol. 1

50. Schwarz J, Tichá H, Tichýa L and Mertens R 2004 J. Optoelectron. Adv. Mater. 6734

51. Hoppe U 1996 J. Non-Cryst. Solids 195138

52. Hudgens J J, Brow R K, Tallant D R and Martin S W 1998 J. Non-Cryst. Solids 22321

53. Scagliotti M, Villa M and Chiodelli G 1987 J. Non-Cryst. Solids 93350

54. Brauer D S, Karpukhina N, Law R V and Hill R G $2010 \mathrm{~J}$. Non-Cryst. Solids 3562626

55. Meyer K 1997 J. Non-Cryst. Solids 209227

56. Šantic A, Moguš-Milankovic A, Furic K, Bermanec V, Kim C W, and Day E 2007 J. Non-Cryst. 3531070

57. Garbarczyk J E, Machowski P, Wasiucionek M, Tykarski L, Bacewicz R and Aleksiejuk A 2000 Sol. State Ionics 1361077

58. Brow R K, Tallant D R, Warren W L, McIntyre A and Day D E 1997 Phys. Chem. Glasses 38300

59. Zotov N, Schlenz H, Brendebach B, Modrow H, Hormes J, Reinauer F, Glaum R, Kirfel A and Paulmann C 2003 Z. Naturforsch. 58(a) 419

60. Magdas D A, Cozar O, Chis V, Ardelean I and Vedeanu N 2008 Vib. Spectrosc. 48251 